\title{
The RIO protein kinase-encoding gene Sj- riok-2 is involved in key reproductive processes in Schistosoma japonicum
}

\author{
Lu Zhao ${ }^{1}$, Xin He ${ }^{1}$, Christoph G. Grevelding ${ }^{2}$, Qing Ye ${ }^{1}$, Ying Li ${ }^{1}$, Robin B. Gasser ${ }^{3}$, Colette Dissous ${ }^{4}$,
} Mudassar N. Mughal', Yan-Qin Zhou' ${ }^{1}$ Jun-Long Zhao' and Min Hü ${ }^{1 *}$

\begin{abstract}
Background: Schistosomiasis is one of the most prevalent parasitic diseases worldwide and is caused by parasitic trematodes of the genus Schistosoma. The pathogenesis of schistosomiasis is caused by eggs whose production is the consequence of the pairing of schistosomes and the subsequent sexual maturation of the female. Previous studies have demonstrated that protein kinases are involved in processes leading to the male-induced differentiation of the female gonads, ovary and vitellarium. Right open reading frame protein kinase 2 (RIOK-2) is a member of the atypical kinase family and shown in other organisms to be responsible for ribosomal RNA biogenesis and cell-cycle progression, as well as involves in nematode development. However, nothing is known about its functions in any trematode including schistosome.
\end{abstract}

Methods: We isolated and characterized the riok-2 gene from S. japonicum, and detected the transcriptional profiles of Sj-riok-2 by using real-time PCR and in situ hybridization. RNAi-mediated knockdown of Sj-riok-2 was performed, mitotic activities were detected by EdU incorporation assay and morphological changes on organs were observed by confocal laser scanning microscope (CLSM).

Results: In silico analyses of the amino acid sequence of Sj-RIOK-2 revealed typical features of this class of kinases including a winged helix (wHTH) domain and a RIO kinase domain. Sj-riok-2 is transcribed in different developmental stages of $\mathrm{S}$. japonicum, with a higher abundance in adult females and eggs. Localization studies showed that Sj-riok-2 was mainly transcribed in female reproductive organs. Experiments with adult schistosomes in vitro demonstrated that the transcriptional level of Sj-riok-2 was affected by pairing. Knocking down Sj-riok-2 by RNAi reduced cell proliferation in the vitellarium and caused the increased amount of mature oocytes in ovary and an accumulation of eggs within the uterus.

Conclusions: Sj-riok-2 is involved in the reproductive development and maturation of female S. japonicum. Our findings provide first evidence for a pairing-dependent role of Sj-riok-2 in the reproductive development and maturation of female $S$. japonicum. Thus this study contributes to the understanding of molecular processes controlling reproduction in schistosomes.

Keywords: Schistosoma japonicum, RIO2 kinase, RNA interference, Gonad, Reproductive development

\footnotetext{
* Correspondence: mhu@mail.hzau.edu.cn

${ }^{1}$ State Key Laboratory of Agricultural Microbiology, College of Veterinary

Medicine, Huazhong Agricultural University, Wuhan, People's Republic of

China

Full list of author information is available at the end of the article
} 


\section{Background}

Schistosomiasis is a serious disease caused by parasitic flatworms of the genus Schistosoma, and it affects more than 230 million people in 78 countries around the world [1]. The control of this disease mainly relies on chemotherapy, as no vaccine is available [2]. However, although the drug praziquantel (PZQ) is widely used against all Schistosoma species, it cannot prevent reinfection $[3,4]$. In addition, accumulated evidence indicates that resistance to this drug might occur [5-10]. Therefore, alternative treatment strategies are required for controlling the parasite. To this end, research activities aim at understanding biological processes in schistosomes at the molecular level. As schistosomiasis is associated with granulomatous inflammatory responses in different host tissues, including liver, the intestinal tract and spleen (hepato-intestinal form) or the urinary bladder and/or genital tract (urogenital form), are induced by eggs deposited by female schistosomes [11], research efforts have focused on identifying processes responsible for growth and reproduction. The latter is of specific interest, because the pairing of females with male schistosomes is unique with respect to physiological consequences. Unpaired, virgin-like females possess stem cell-like precursor vitelline cells and a small ovary containing stem cell-like precursor oocytes, the oogonia. Pairing induces mitoses and differentiation processes that lead to the completion of the development of the female gonads, ovary and vitellarium. Both organs deliver cells, mature oocytes and $\mathrm{S} 4$ vitelline cells, respectively, needed for the synthesis of composite eggs [12-14]. Among others, signal transduction processes have been detected to be involved in male-female interactions controlling oocyte and vitelline cell differentiation [15-17].

In this context, cellular protein kinases PKs represent intensively studied class of molecules. As demonstrated in model organisms and eukaryotic cell cultures, PKs are essential for regulating various cellular processes, such as transcription, cell cycle progression, cytoskeletal rearrangement and metabolic processes $[18,19]$. Based on their structure, PKs can be classified into eukaryotic protein kinase (ePK) and atypical protein kinase (aPK) [18, 19]. More than $90 \%$ of human PKs are ePKs, which are characterized by the presence of a "catalytic domain", containing 11 major conserved sub-domains which are separated by regions of lower conservation and important for substrate binding [18]. The aPKs share a homologous catalytic core-structure with ePKs, but exhibit limited overall sequence similarity [20]. In schistosomes, several ePKs such as Src-like tyrosine PKs, Syk-like PK, Src/Fyn-like hybrid PK, Src/Abl- and Abl-like PKs, cyclic guanosine-3',5' -monophosphate dependent protein kinase (cGKs), mitogen-activated PKs (MAP), protein kinases C (PKCs), extracellular signal-regulated kinases (ERKs) and Polo-like kinase (PLK) were found to be specifically or predominantly expressed in gonads, and proven to be involved in reproductive development and egg production by functional analyses [21-31]. Although the Venus kinase receptor (an atypical receptor tyrosine kinase) and an atypical protein kinase $C$ had been demonstrated to play important roles in the reproduction and viability of schistosomes [32], there is still limited information about the functions or roles of other aPKs in reproductive development in schistosomes.

One family of aPKs are the RIO (right open reading frame) kinases, which were first characterized in yeast [33]. To date, four members of the RIO-kinase family, RIOK-1, RIOK-2, RIOK-3 and RIOK-B, have been identified $[34,35]$. As a non-ribosomal factor required for normal ribosomal RNA biogenesis, RIOK-2 has been shown to be indispensable for $18 \mathrm{~S}$ pre-rRNA production and cytoplasmic $40 \mathrm{~S}$ ribosomal subunit maturation in both yeast and human cells [36-39]. In yeast, RIOK-2 as an assembly factor is associated with pre-40S subunit to prevent premature translation initiation [40, 41]. In addition, RIOK-2 exerts important roles in cell cycle progression in different cancer cells [42, 43]. The RIOK2-encoding gene riok-2 is transcribed in different developmental stages of parasitic nematodes [44, 45] and is crucial for larval growth and development in Caenorhabditis elegans [46, 47]. However, nothing is known about the function(s) of RIOK-2 in any trematode.

In the present study, we characterized the RIOK-2encoding gene of Schistosoma japonicum (Sj-riok-2). In addition to cloning, in silico analyses, and transcriptional profiling, different physiological and morphological techniques were applied to demonstrate that Sj-riok-2 contributes to male-female interaction in $S$. japonicum and to important roles in female reproductive development and fertility.

\section{Methods \\ Parasite material}

Snails (Oncomelania hupensis) infected with S. japonicum (Jiangsu Provincial Institute of Parasitic Disease Control and Prevention, China) were maintained in water and illuminated for $2-4 \mathrm{~h}$ at $25{ }^{\circ} \mathrm{C}$ to induce the shedding of cercariae [48]. Six- to eight-week-old Kunming female mice (Hubei Provincial Center for Disease Control, China) were infected percutaneously with 2000-3000 cercariae (for the subsequent collection of skin- and lung-stage schistosomula) or $30 \pm 5$ cercariae (for the collection of hepato-portal schistosomula, adults and eggs) per mouse. Skin-stage schistosomula were recovered directly from crushed skin from the mice infected for $3 \mathrm{~h}$ and incubated with Earle's equilibrium liquid. Lung-stage schistosomula were collected from 
crushed lung pieces incubated with Earle's equilibrium liquid following right ventricular-pulmonary artery perfusion of the mice that had been infected for $3 \mathrm{~d}$ [48]. Hepato-portal schistosomula and adults were collected by hepato-portal perfusion of mice that had been infected for 21, 28, 35, 42 and 49 d, respectively [48]. Eggs were harvested from the livers of the mice infected for 35-49 d by comminution and layered-filtration with nylon mesh $[48,49]$. For total RNA isolation, individual developmental stages collected were washed with diethypyrocarbonate (DEPC) water twice and preserved in TRIzol Reagent (Invitrogen, Carlsbad, CA) at $-80{ }^{\circ} \mathrm{C}$.

\section{In silico analyses}

The expressed sequence tag (EST) sequence of Sj-riok-2 (GenBank accession no. AY814262.1) was obtained by using the BlastN algorithm (https://blast.ncbi.nlm.nih.gov/Blast.cgi). The cDNA sequence that mapped to the gene in the draft genome was obtained from the $S$. japonicum genome of WormBase ParaSite (http://parasite.wormbase.org/ftp.html). Exon-intron boundaries in genomic sequences were determined by blast analyses using cDNA sequences as probes. The $\mathrm{Sj}$-RIOK-2 protein sequence was aligned with orthologs of selected species by employing PROSITE [50] (www.expasy.ch/tools/ scnpsit1.html), Pfam [51] (www.sanger.ac.uk/Software/ $\mathrm{Pfam} /$ ), and Clustal Omega alignment of European Bioinformatics Institute (www.ebi.ac.uk/Tools/msa/clustalo/). Functional domains and sub-domains were identified based on the protein alignment.

The amino acid sequences of 14 orthologs were retrieved from the GenBank database for further phylogenetic analysis, which was performed by using the MEGA 5 neighbor joining (NJ) method [52]. The species selected were nine invertebrates including Brugia malayi (CRZ23003.1), Clonorchis sinensis (GAA29846.2), Caenorhabditis elegans (CAC70109.2), Drosophila melanogaster (NP_651365.1), Haemonchus contorts (ADW27445.1), Loa loa (EFO24525.1), Schistosoma haematobium (XP_012792720.1), S. mansoni (CCD79377.1), Strongyloides ratti (CEF64700.1) and four vertebrates including Danio rerio (NP_998719.2), Homo sapiens (NP_060813.2), Mus musculus (NP_080210.1), Xenopus tropicalis (NP_001016682.1), and yeast Saccharomyces cerevisiae (KZV08416.1). Confidence limits were assessed by bootstrapping using 1000 pseudo-replicates for NJ, and other settings were obtained using the default values in MEGA v.5.0. A $50 \%$ cut-off value was implemented for the consensus tree [52].

\section{Rapid amplification of CDNA ends (RACE) and cloning of the Sj-riok-2 cDNA}

Total RNA of adult $S$. japonicum worms was isolated by TRIzol (Invitrogen, NY, USA) according to the manufacturer's instructions. Total 3'-ends cDNA was synthesized using Sj-riok-2-specific internal primers (Sjriok2-1F and Sjriok2-3F, Additional file 1: Table S1) using the SMARTer $^{\text {mM }}$ RACE cDNA Amplification Kit (Clontech Laboratories, CA, USA). The cycling conditions for 3' RACE-PCR were as follows: denaturation at $94{ }^{\circ} \mathrm{C}$ for 3 min followed by 5 cycles at $66^{\circ} \mathrm{C} / 63{ }^{\circ} \mathrm{C}$ for $30 \mathrm{~s}, 72{ }^{\circ} \mathrm{C}$ for $2 \mathrm{~min}$, and 30 cycles at $94{ }^{\circ} \mathrm{C}$ for $30 \mathrm{~s}, 64{ }^{\circ} \mathrm{C} / 61^{\circ} \mathrm{C}$ for $30 \mathrm{~s}, 72{ }^{\circ} \mathrm{C}$ for $2 \mathrm{~min}$, with a final extension at $72{ }^{\circ} \mathrm{C}$ for $10 \mathrm{~min}$. After cloning and sequencing, the sequence amplified by 3' RACE-PCR was merged to the known sequence region to generate a full-length Sj-riok-2 sequence. For verification of the entire putative open reading frame (ORF), two additional primers Sjriok2ORF-F and Sjriok2-ORF-R (Additional file 1: Table S1) were designed based on the reconstructed full-length sequence. The amplification conditions for the PCR following the reverse-transcription reaction (PrimeScript 1st Strand cDNA Synthesis Kit) were as follows: $94{ }^{\circ} \mathrm{C}$ for $3 \mathrm{~min}$ followed by 35 cycles at $94{ }^{\circ} \mathrm{C}$ for $30 \mathrm{~s}$, $60{ }^{\circ} \mathrm{C}$ for $30 \mathrm{~s}, 72{ }^{\circ} \mathrm{C}$ for $2 \mathrm{~min}$, with a final extension at $72{ }^{\circ} \mathrm{C}$ for $10 \mathrm{~min}$. The PCR product was cloned into pMD19-T (Takara Biotechnology, Dalian, China) and then sequenced to confirm the integrity of the fulllength sequence. The full Sj-riok-2 cDNA sequence was deposited in GenBank with the accession no. KY884990.

\section{Quantitative real time PCR}

Total RNA was isolated from cercariae, skin and lungstage schistosomula, hepato-portal worms, adult female and adult male worms as well as eggs. The cDNAs were produced by RNA reverse transcription following PrimeScript $^{\text {tix }}$ RT Reagent Kit with the gDNA Eraser procedure (Takara, Dalian, China) and used as templates for PCR amplification using the SYBR Green PCR Master Mix (Takara, Dalian, China) and the ABI 7500 detection system (Applied Biosystems, USA). $\beta$-tubulin was used as an internal standard control (GenBank: AY220457.2) $[53,54]$. Two pairs of primers were designed to Sj-riok-2 (riok2-F and riok2-R), Sj-plk-1 (plk1-F and plk1-R) and Sj- $\beta$-tubulin ( $\beta$-Tubulin-F and $\beta$-Tubulin-R), respectively (Additional file 1: Table S1). Reactions $(10 \mu \mathrm{l})$ were repeated in triplicate under the following conditions: $50{ }^{\circ} \mathrm{C}$ for $2 \mathrm{~min}$, followed by $95{ }^{\circ} \mathrm{C}$ for $30 \mathrm{~s}$, then 40 cycles of $95{ }^{\circ} \mathrm{C}$ for $15 \mathrm{~s}, 58{ }^{\circ} \mathrm{C}$ for $15 \mathrm{~s}$, and $72{ }^{\circ} \mathrm{C}$ for $20 \mathrm{~s}$, followed by a final $10 \mathrm{~min}$ elongation step at $72{ }^{\circ} \mathrm{C}$. For the analysis of the data and graphical representation, the $2^{-\triangle \Delta C t}$ method was used [55]. Cercariae were used as a calibrator and statistical analyses were given as the mean \pm standard deviation and differences among different stages by using One-Way Analysis of Variance (ANOVA) for statistical analysis. A $P$ value of $\leq 0.05$ was considered as statistically significant. 


\section{In situ hybridization}

In situ hybridization experiments were performed to localize Sj-riok-2 mRNA in male and female parasites using an established approach $[26,56]$. In brief, adult worm pairs were fixed in Bouin's solution (picric acid/ acetic acid/formaldehyde; 15/1/5) and subsequently embedded in paraplast (Sinopharm) overnight. Five micrometers paraffin-sections of adult worms were incubated in xylol before rehydration with a graded ethanol series (100-30\%) and then treated with proteinase $\mathrm{K}$ to remove protein (final concentration $1 \mu \mathrm{g} / \mathrm{ml}$ ). For RNA probe preparation, complementary DNA fragments of Sj-riok-2 (nt positions 1146-1481) and an eggshell gene (p14 ortholog from S. mansoni) of S. japonicum (Sj-es, GenBank: M59318.1; nt positions 440-809) [57] were synthesized to produce templates for probe labeling by PCR with the primers tagged with T7 and SP6 promoter sequences (underlined bases) (Additional file 1: Table S1). Sense and antisense transcripts were labeled with digoxigenin following the instructions of the manufacturer (Roche Applied Science, Basel, Switzerland). Labeled transcripts of Sj-riok-2 and Sj-es gene were sizecontrolled by gel electrophoresis. The sections were hybridized in hybridization solution containing $100 \mu \mathrm{l}$ of deionized formamide, $50 \mu \mathrm{l}$ of $20 \times \mathrm{SSC}, 4 \mu \mathrm{l}$ of $50 \times$ Denhardt's solution, $2 \mu \mathrm{l}$ of Tween $20,4 \mu \mathrm{l}$ of denatured salmon sperm DNA $(10 \mathrm{mg} / \mathrm{ml}), 8 \mu \mathrm{l}$ of yeast RNA $(33 \mathrm{mg} / \mathrm{ml})$ and $6 \mu \mathrm{l}$ of each specific antisense or sense probe. The probes were heated at $70{ }^{\circ} \mathrm{C}$ for $10 \mathrm{~min}$ before use and DEPC-treated $\mathrm{H}_{2} \mathrm{O}$ added to a final volume of $200 \mu \mathrm{l}$ at $42{ }^{\circ} \mathrm{C}$ for $16 \mathrm{~h}$ in a wet chamber containing $20 \%$ glycerol. Then, the sections were washed with $2 \times \mathrm{SSC}, 1 \times \mathrm{SSC}$ and $0.5 \times \mathrm{SSC}$ for $15 \mathrm{~min}$ each and blocked with $2 \%$ blocking reagent (Roche Applied Science, Basel, Switzerland) at $22-25{ }^{\circ} \mathrm{C}$ (room temperature, RT) for $30 \mathrm{~min}$. The detection of digoxigenin-labeled transcript was done using alkaline phosphatase conjugated anti-digoxigenin antibodies (1:1000) in 1\% blocking solution. Unbound antibodies were removed by washing with maleic acid solution twice for 20 min each. Then colour reaction was developed with naphthol-AS-phosphate and Fast Red TR (Sigma, USA) in the dark. The worm sections were covered with a cover slip and sealed with water soluble sealing medium (Boster, China) and air-dried. Finally, the staining location and intensity were observed under microscope (E80i, Nikon, Japan) at 20- and 40-times magnification.

\section{Pairing experiments in vitro}

Adult worms collected from mice $42 \mathrm{~d}$ after infection were cultured at $37{ }^{\circ} \mathrm{C}$ in vitro in 841 medium ( $\mathrm{pH}$ 7.4) consisting of RPMI 1640 medium (Invitrogen, USA) supplemented with $10 \% \mathrm{~V} / \mathrm{V}$ new born calf serum (Gibco, New Zealand), $1 \mathrm{mg} / \mathrm{ml}$ lactalbumin hydrolysate, $10^{-6}$ $\mathrm{mol} / \mathrm{l}$ hydrocortisone, $5 \times 10^{-7} \mathrm{~mol} / \mathrm{l}$ hypoxanthine, $10^{-6}$ $\mathrm{mol} / \mathrm{l}$ serotonin, $100 \mathrm{U} / \mathrm{ml}$ penicillin and $100 \mu \mathrm{g} / \mathrm{ml}$ streptomycin.

For pairing experiments, 10 pairs of worms as well as 10 single females and 10 single males were cultured in supplemented 841 medium for $3 \mathrm{~d}$ and $9 \mathrm{~d}$. The medium was changed every 2 days. In addition to paired cultured and single cultured groups, the re-mating group was also set up. At first, single females and single males were cultured separately for $2 \mathrm{~d}$. On the third day, single females and males were co-cultured together for $24 \mathrm{~h}$, and remated pairs were selected for continued culturing for 6 d. At each time point (3 d and $9 \mathrm{~d}$ ), couples (for control), re-paired worms, single females or single males were collected for real-time PCR analyses. Female and male worms from couples were used as calibrators, and statistically significant difference were determined by two-way ANOVA analysis.

\section{RNAi-mediated knock down of Sj-riok-2 expression in vitro}

Complementary DNA fragments of Sj-riok-2 (1811 bp) and Sj-plk-1 (1701 bp, PLK-1-encoding gene of S. japonicum) were synthesized, respectively, to produce templates (for dsRNA synthesis) by PCR with the following primer combinations: dsRNA-riok2-F/dsRNA-riok2-R and dsRNA-plk1-F/ dsRNA-plk1-R tagged with T7 and SP6 promoter sequences (underlined bases) (Additional file 1: Table S1). The primer pair dsRNA-stk6-F and dsRNA-stk6-R (Additional file 1: Table S1) designed to amplify Sj-stk-6 (Tyrosine kinase 6 encoding gene of S. japonicum) generated a 1111 bp product that was used as a negative-control. The cycling conditions for the amplification of the Sj-riok-2 region were an initial denaturation step at $94{ }^{\circ} \mathrm{C}$ for $3 \mathrm{~min}$, followed by $35 \mathrm{cy}$ cles at $94{ }^{\circ} \mathrm{C}$ for $40 \mathrm{~s}, 64{ }^{\circ} \mathrm{C}$ for $40 \mathrm{~s}$ and $72{ }^{\circ} \mathrm{C}$ for $2 \mathrm{~min}$, with a final extension at $72{ }^{\circ} \mathrm{C}$ for $10 \mathrm{~min}$. The cycling conditions for $S j-p l k-1$ were an initial denaturation step at $94{ }^{\circ} \mathrm{C}$ for $3 \mathrm{~min}$, followed by 5 cycles at $94{ }^{\circ} \mathrm{C}$ for $40 \mathrm{~s}$, $61{ }^{\circ} \mathrm{C}$ for $30 \mathrm{~s}$ and $72{ }^{\circ} \mathrm{C}$ for $2 \mathrm{~min}, 30$ cycles at $94{ }^{\circ} \mathrm{C}$ for $30 \mathrm{~s}, 63{ }^{\circ} \mathrm{C}$ for $30 \mathrm{~s}$ and $72{ }^{\circ} \mathrm{C}$ for $2 \mathrm{~min}$ with a final extension at $72{ }^{\circ} \mathrm{C}$ for $10 \mathrm{~min}$. The cycling conditions for Sj-stk-6 were an initial denaturation step at $94{ }^{\circ} \mathrm{C}$ for 3 min followed by 35 cycles at $94{ }^{\circ} \mathrm{C}$ for $40 \mathrm{~s}, 65^{\circ} \mathrm{C}$ for $40 \mathrm{~s}$ and $72{ }^{\circ} \mathrm{C}$ for $2 \mathrm{~min}$, with a final extension at $72{ }^{\circ} \mathrm{C}$ for $10 \mathrm{~min}$. Each PCR product was cloned into pMD$19 \mathrm{~T}$ and directly sequenced. Linearized plasmids obtained by a restriction enzyme downstream of the vector were used as templates for in vitro transcriptions to generate single-stranded RNAs. The reaction volume $(20 \mu \mathrm{l})$ contained $1.5 \mu \mathrm{g}$ of linearized plasmids, $2 \mu \mathrm{l} 10 \times$ Reaction Buffer, $2 \mu \mathrm{l} \mathrm{A/C/G/UTP} \mathrm{T7} \mathrm{and} 2 \mu \mathrm{l}$ T7/SP6 RNA polymerase mix (MEGAscript RNA transcription kit, Invitrogen, USA). Equal amounts of the single-stranded 
RNAs were mixed into annealing buffer $(500 \mathrm{mM}$ potassium acetate, $19 \mathrm{mM}$ magnesium acetate, $150 \mathrm{mM}$ HEPES-KOH, pH 7.4) and incubated at $90{ }^{\circ} \mathrm{C}$ for $8 \mathrm{~min}$ and subsequently placed at RT for $2-4 \mathrm{~h}$. The integrities of ssRNA and dsRNA molecules were confirmed by agarose gel electrophoresis.

For RNAi experiments, 28 d old schistosomes were cultured in 6-well cell-culture plates, and each well contained five worm couples in $5 \mathrm{ml}$ medium 841 and 10$20 \mu \mathrm{g}$ dsRNA. The experimental setup comprised different groups of worms including couples treated with $10 \mu \mathrm{g}$ Sj-riok-2 dsRNA, or $10 \mu \mathrm{g}$ Sj-plk-1 dsRNA, or $10 \mu \mathrm{g}$ Sj-riok-2 plus $10 \mu \mathrm{g}$ Sj-plk-1 dsRNA, respectively. Control groups included couples treated with $10 \mu \mathrm{g} \mathrm{Sj-}$ stk-6 dsRNA, which is directed against a non-related Src/Abl hybrid kinase [22] or couples which were not treated with any dsRNA (control). All parasites were cultured at $37{ }^{\circ} \mathrm{C}$ for $9 \mathrm{~d}$. The culture medium was changed every 2 days (the new culture media and dsRNA were added together to replace the old media). Parasites cultured for $9 \mathrm{~d}$ were harvested for real-time PCR analysis of Sj-riok-2 mRNA level and morphological analysis. Non-treated females and males were used as calibrators, and statistically significant differences were determined by two-way ANOVA analysis.

\section{5-ethynyl-2'-deoxyuridine (EdU)-incorporation assay}

Paired worms treated with dsRNA for $9 \mathrm{~d}$ were incubated with $10 \mu \mathrm{M}$ of the thymidine analog EdU in medium 841 for $24 \mathrm{~h}$. EdU incorporation was detected by using Click-iT $\mathrm{T}^{\bullet}$ EdU Imaging Kits (Invitrogen, USA) using a previously described method [58]. Paired worms were separated and fixed in phosphate-buffered saline (PBS) containing $0.3 \%$ Triton X-100 (PBSTx) and $4 \%$ paraformaldehyde for $6 \mathrm{~h}$ at RT. After being rinsed in PBSTx, the worms were dehydrated in $50 \%$ and $100 \%$ methanol for $10 \mathrm{~min}$. Then, worms were rehydrated with $50 \%$ methanol and washed in PBSTx for $10 \mathrm{~min}$. Protease $\mathrm{K}(6 \mu \mathrm{g} / \mathrm{ml})$ was added to the worms, which were kept for $25 \mathrm{~min}$ at RT for protein digestion. Subsequently, the worms were fixed with $4 \%$ paraformaldehyde in PBSTx for $10 \mathrm{~min}$ and then rinsed twice in PBS containing 3\% BSA. After being incubated in the click-it reaction cocktail for $30 \mathrm{~min}$ (shaking), the worms were rinsed twice again in PBS containing 3\% BSA and stained with Hoechst 33342 (diluted 1:2000 in PBS) in the dark for $30 \mathrm{~min}$ at RT or overnight at $4{ }^{\circ} \mathrm{C}$. The specimens were examined by confocal laser scanning microcopy (CLSM) using an Olympus FV1000 confocal microscope with $405 \mathrm{~nm}$ (for Hoechst) and $633 \mathrm{~nm}$ (for Alexafluor 647) laser stimulation, respectively, after being washed and mounted with Anti-fade Mounting Medium (Beyotime, China).

\section{Morphological analysis}

The procedure was performed as previously described [21] with minor modifications. Briefly, collected worms were fixed with AFA (95\% ethanol, 3\% formaldehyde and $2 \%$ glacial acetic acid) for at least $24 \mathrm{~h}$ and stained with $0.25 \%$ chloride carmine (Solarbio, China) for $30 \mathrm{~min}$. After destaining in $70 \%$ ethanol with $1 \%$ hydrochloric acid, the worms were dehydrated in $70 \%, 90 \%$ and $100 \%$ ethanol for $3 \mathrm{~min}$ each. Then, worms were cleared in methyl salicylate and preserved as whole mounts with neutral resins on glass slides. Specimens were examined using a confocal laser microscope (Olympus FV1000) under reflection mode employing a $488 \mathrm{~nm} \mathrm{He} / \mathrm{Ne}$ laser.

\section{Results}

Cloning and sequence analysis suggest that Sj-riok-2 is a member of the RIO-kinase family

The cDNA of Sj-riok-2 (GenBank: KY884990) is 2164 bp long, containing a 1476 bp open reading frame (ORF) that encodes 491 amino acids, a 344 bp 5'-UTR, and a 344 bp 3'-UTR including the poly-A tail preceded by a non-canonical poly-adenylation signal (ATTAAA) $40 \mathrm{bp}$ upstream. The genomic DNA of Sj-riok-2 is more than $11,082 \mathrm{bp}$ in length, and is composed of 7 exons varying from $69 \mathrm{bp}$ to $350 \mathrm{bp}$ in length and 6 introns varying from 36 bp to 4751 bp in length (Fig. 1). All exon-intron junctions follow the GT-AG rule.

In silico analyses showed that the $\mathrm{Sj}$-RIOK-2 has high sequence identity to other RIOK-2 orthologs from $S$. mansoni (76\%), S. haematobium (70\%), C. elegans (66\%), $H$. sapiens (52\%) and D. melanogaster (50\%). Protein sequence alignment (Fig. 2) confirmed that Sj-RIOK-2 shares conserved regions, including the $\mathrm{N}$-terminal located winged helix (wHTH) region (amino acid (aa) positions 1-96), an ATP-binding motif (positions 105-118), a flexible loop (positions 151-165), a hinge region (positions 209-221), a catalytically active site (positions 257-270) and a metal binding loop (positions 287-299). In addition, the RIOK-2-specific motif G-x-GKES, which is highly conserved in the N-terminal part of the ATP-binding motif [35], and the autophosphorylation site, which exhibits a slightly altered RLGRTSFRKVK sequence [34, 35], were found in the flexible loop. The key residues "Asp" and "Asn" responsible for phosphoryl transfer, which are involved in catalytic function and are conserved in all ePKs $[18,59]$, were also found in the active sites of Sj-RIOK-2 (D262, N267). A conserved residue "Asp", required for the positioning of metal ions [35], was detected within metalbinding motif (D290) (Fig. 2).

Phylogenetic analyses (Fig. 3) of orthologous amino acid sequences from 13 selected species showed that $\mathrm{Sj}$ RIOK-2 grouped together with orthologs from S. haematobium, S. mansoni and C. sinensis with strong (100\%) nodal support, to the exclusion of RIOK-2 s from 

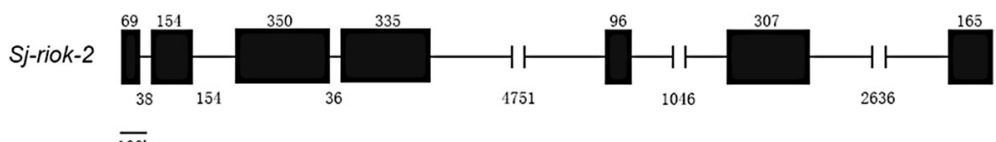

$100 \mathrm{bp}$

Fig. 1 Schematic diagram showing the genomic organization of riok-2 of Schistosoma japonicum. Black boxes indicate exons, with the numbers above indicating the length (bp) of an exon. Introns are indicated by slanted lines between the exons, with the numbers indicating intron length (bp)

vertebrates, including mammals, fish and amphibians, which also grouped together with high bootstrap support (100\%). All RIOK-2 s representing nematodes formed a cluster with $96 \%$ support.

Transcriptional profiling confirmed Sj-riok-2 transcripts in all life-cycle stages and a gonad-preferential expression in adult females and males

Sj-riok-2 transcripts were detected in different developmental stages of $S$. japonicum by qRT-PCR, in which cercariae were used as a calibrator (Fig. 4). The results showed that Sj-riok-2 was most abundantly transcribed in $42 \mathrm{~d}$ adult female worms and eggs. The skin- $(3 \mathrm{~h})$ and lung- ( $3 \mathrm{~d}$ ) stage schistosomula contained a similar abundance of Sj-riok-2 transcripts as the hepato-portal worms (21 d). Compared with adult males, the transcription level in females was 4.7-, 13.7- and 22-fold higher in 35, 42 and $49 \mathrm{~d}$ old worms $\left(F_{(11,23)}=223.75, P<0.0001\right)$.

The transcription of Sj-riok-2 in adult worms was localized by in situ hybridization. Employed as a positive
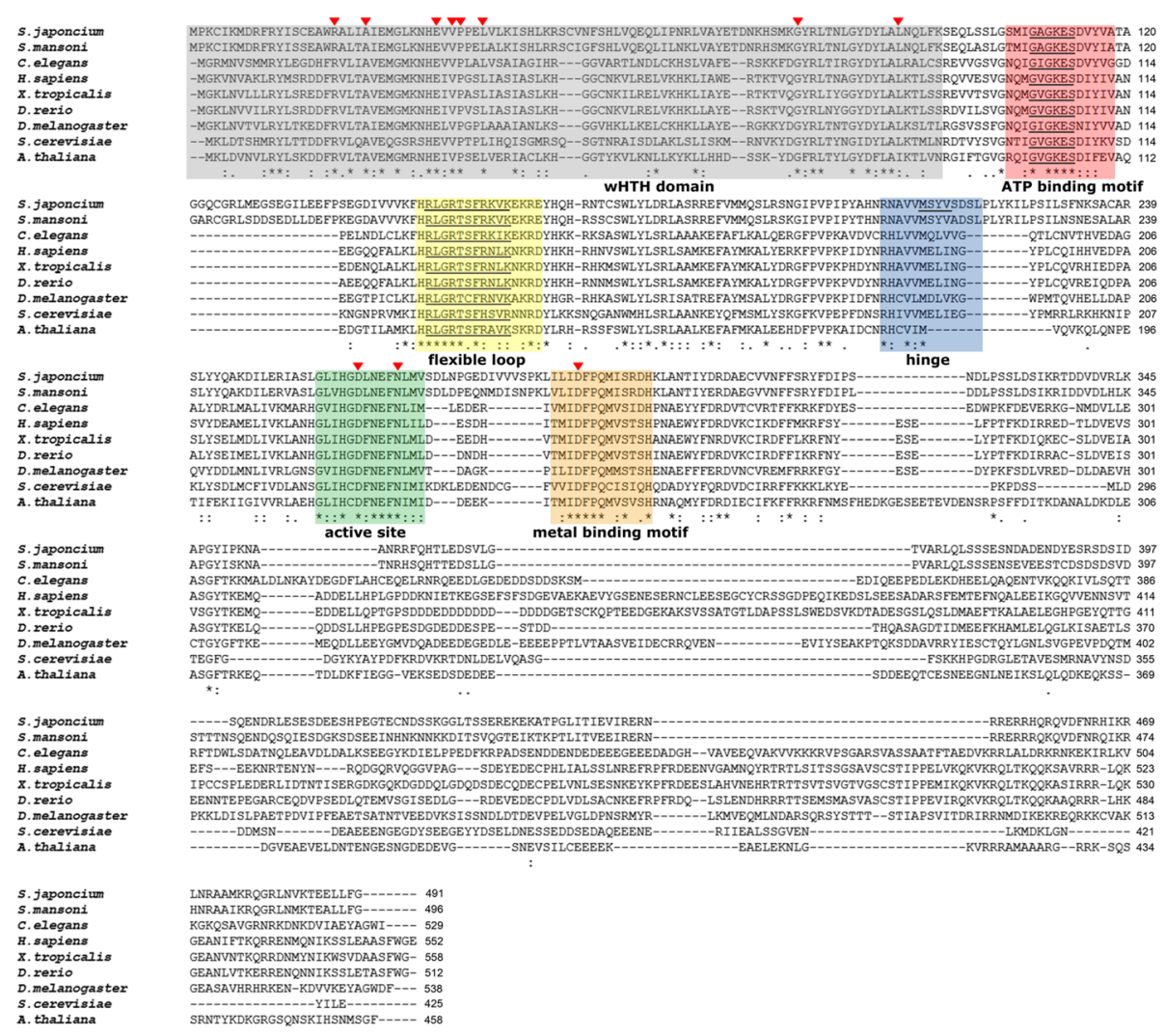

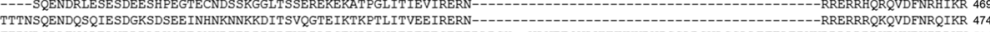
RETDWLSDATNQLEAVDLDALKSEEGYKDIELPPEDFKR PADSENDDENDEDEEEGEEEDADGH--VAVEBQVAKVVKKKRVPSGARSVASSAATFTAEDVKRRLALDRKRNKEKTRLKV 504

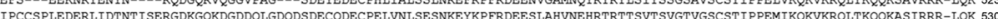
EENNTEPEGARCEQDVPSEDLQTEMVSGISEDLG---RDEVEDEC PDVVDLSACNKEFRPERDQ--LSLENDHRRRTTSEMSMASVASCSTIPPEVIRQKVKRQLTKOOKAARRRR-LHK 430 PKKLDISLPAETPDVIPFEAETSATNTVEEDVKSISSNDLDTDEVPELVGLDENSRMYR-------LKMVEQMLNDARSQRSYSTTT--STIAPSVITDRIRRNMDIKEKREQRKKCVAK 513 -

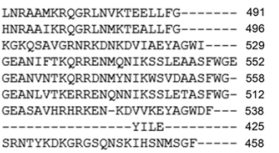

Fig. 2 Alignment of the inferred amino acid sequences of Schistosoma japonicum Sj-RIOK-2 with RIOK-2 orthologs of eight other species. The eight selected species are Schistosoma mansoni (CCD79377.1, Sm-RIOK-2), Caenorhabditis elegans (CAC70109.2, Ce-RIOK-2), Homo sapiens (NP_060813.2, Hs-RIOK-2), Xenopus tropicalis (NP_001016682.1, Xr-RIOK-2), Danio rerio (NP_998719.2, Dr.-RIOK-2), Drosophila melanogaster (NP_651365.1, Dm-RIOK-2), Saccharomyces cerevisiae (CAC70109.2, Sc-RIOK-2), Arabidopsis thaliana (AEE78772.1, At-RIOK-2). Functional domains including the $\mathrm{wHTH}$ region (grey), ATP binding motif (red), flexible loop (yellow), hinge region (blue), active site (green), metal binding motif (orange) are highlighted and labeled below the alignment. Red arrows indicate conserved residues within the wHTH domain and "Asp" and "Asn" residues responsible for phosphoryl transfer exits within the active site, and "Asp" required for the positioning of metal ions exits within the metal binding motif. Asterisks under the alignment indicate identical residues. ":" represents strong similarity, "." represents weak similarity, and a lack of a symbol indicates no similarity among residues 


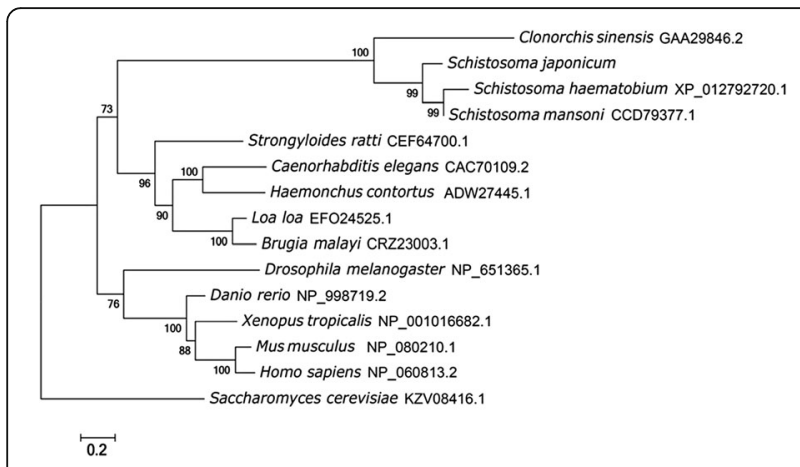

Fig. 3 The neighbor-joining (NJ) tree of Schistosoma japonicum RIOK-2 with 13 homologues from 13 selected species. The species selected were nine invertebrates including Brugia malayi (CRZ23003.1), Clonorchis sinensis (GAA29846.2), Caenorhabditis elegans (CAC70109.2), Drosophila melanogaster (NP_651365.1), Haemonchus contorts (ADW27445.1), Loa loa (EFO24525.1), Schistosoma haematobium (XP_012792720.1), Schistosoma mansoni (CCD79377.1), Strongyloides ratti (CEF64700.1) and four vertebrates including Danio rerio (NP_998719.2), Homo sapiens (NP_060813.2), Mus musculus (NP_080210.1), Xenopus tropicalis (NP_001016682.1). The RIOK-2 from Saccharomyces cerevisiae (KZV08416.1) was used as the outgroup. Bootstrap values are displayed above or below the branches

control, the eggshell gene of S. japonicum (Sj-es; p14 ortholog of $S$. mansoni) [57] was only transcribed in mature females (Fig. 5a) and was detected in the vitellarium of adult females (Fig. 5b), which is in accordance with previous reports for S. japoncium and S. mansoni [57, 60]. Sj-riok-2 was also detected in the ovary and

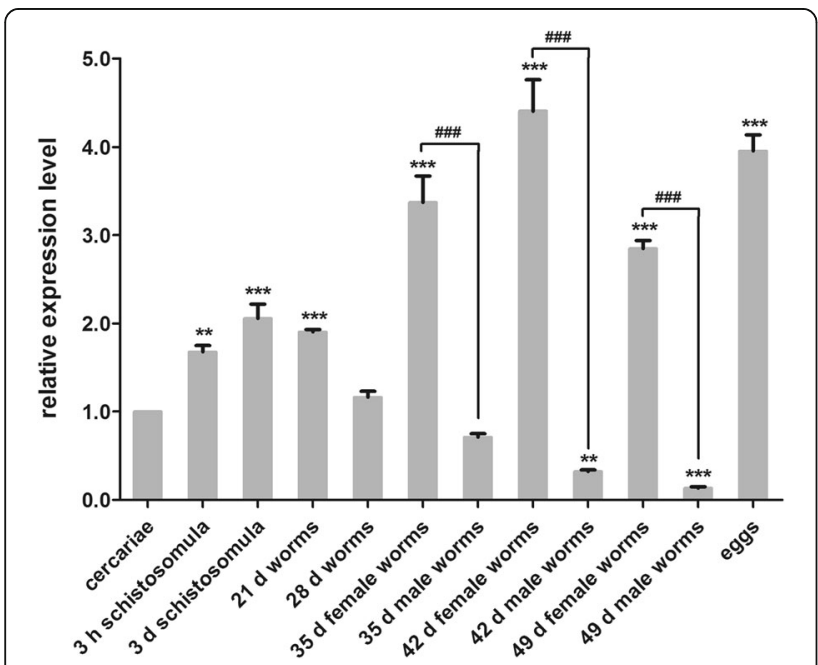

Fig. 4 Transcriptional profiles of Sj-riok-2 detected in different developmental stages of Schistosoma japoncium by real-time PCR. Relative expression levels of transcripts were analyzed by the $2^{-\Delta \Delta C t}$ method, and Sj- $\beta$-tubulin was used as internal standard. Data are representative of the mean \pm SD of three separate experiments. All stages were compared with the cercariae stage, and statistically significant differences are shown as ** $(P=0.001)$ and ${ }^{* * *}(P<0.0001)$; \#\#\# represents the significant difference $(P<0.0001)$ in transcript abundances between female and male worms vitellarium (Figs. 5c-1 and 2). The hybridization signals appeared to be slightly stronger in immature oocytes, which accumulated at the edge of ovary surrounding the large, mature oocytes. In addition, Sj-riok-2 transcripts were also detected in the gastrodermis and the tissues surrounding the ootype, likely including vitelloduct and oviduct (Figs. 5c-2 and 3). The vitelloduct indicates that mature S4 vitelline cells contain Sj-riok-2 transcripts. In males, signals were observed in the testes, although signal intensity was weaker compared with tissues in the females (Fig. 5c-4). This result is in accordance to the qPCR data obtained by the stage-specific expression analysis (Fig. 4).

The transcription level of Sj-riok-2 is influenced by pairing During cultivation, the majority of worms remained in a constant pairing contact. Upon perfusion and culturing, single males started to re-pair with the females after 2$4 \mathrm{~h}$, and about $80 \%$ worms exhibited a pairing status after $12 \mathrm{~h}$ in culture.

The transcript level of Sj-riok-2 in single females was 0.8 -fold and 0.3-fold higher than in paired females after in vitro culture for $3 \mathrm{~d}\left(F_{(1,7)}=7.43, P=0.0295, t_{(5)}=6.045\right.$, $P<0.01)$ and $9 \mathrm{~d}\left(F_{(2,11)}=14.02, P=0.0009, t_{(6)}=0.6936\right.$, $P>0.05$ ), respectively (Fig. 6a). However, the transcription level of Sj-riok-2 in single males was 0.3-fold lower than in the paired males after culture for $3 \mathrm{~d}$ with a nonsignificant difference $(P=0.0759)$ (Fig. 6a). Nevertheless, the transcription level was 0.7 -fold higher in single males after culture for $9 \mathrm{~d}\left(t_{(6)}=3.904, P<0.01\right)$ (Fig. 6b). Interestingly, the transcript levels of Sj-riok-2 in single females and males were significantly decreased after re-pairing with the opposite gender for $6 \mathrm{~d}$. It was significantly lower in females and males after re-pairing compared with females $\left(t_{(6)}=2.269, P<0.05\right)$ and males $\left(t_{(6)}=5.291\right.$, $P<0.001$ ) cultured separately (Fig. 6b).

\section{RNAi-induced knockdown of Sj-riok-2 demonstrated its involvement in processes controlling mitosis and female gonad-differentiation in adult S. japonicum}

A gene silencing approach was performed to obtain evidence for the function of Sj-riok-2. Due to the presence of transcripts in the gonads, and due to evidence in the literature $[42,43]$ indicating that RIOK-2 was identified as a substrate of mitotic kinase PLK-1 (Polo-Like Kinase 1) in HeLa cells and can be involved in cell-cycle processes, we considered the possibility that this gene may be involved in reproductive processes such as cell proliferation activities in gonadal cells. In an independent study [24], functional evidence indicated that the activity of the PLK-1-encoding gene Sm-plk-1 is important for cell-cycle progression in gonadal cells of $S$. mansoni. Therefore, we used the PLK-1 encoding gene of $S$. japonicum, Sj-plk-1, as control for comparing effects. The 
a

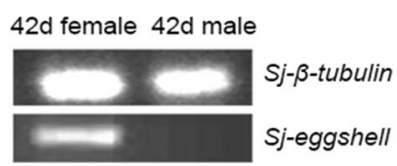

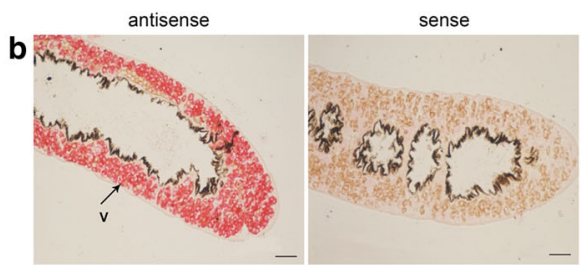

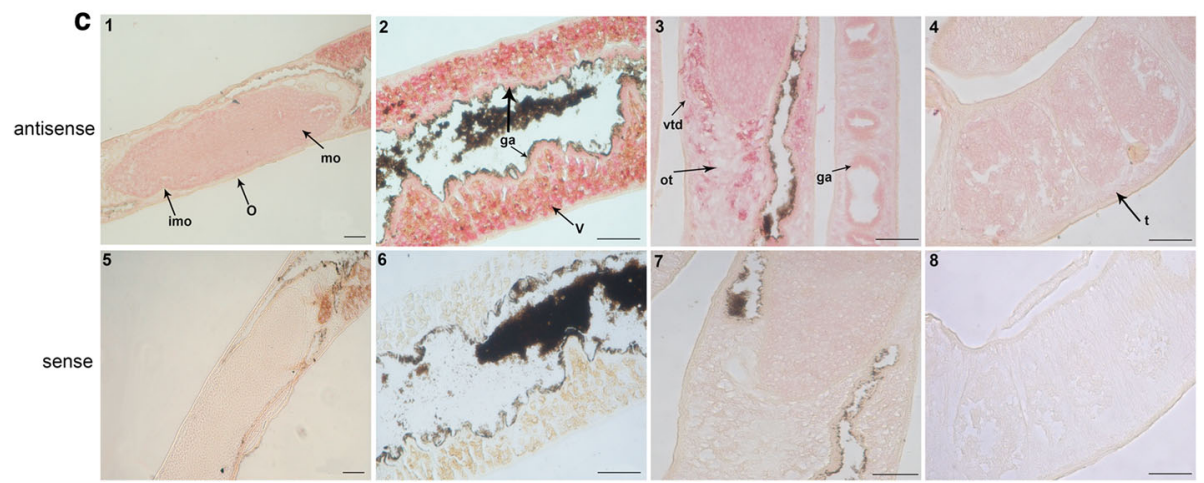

Fig. 5 Transcription localization of Sj-riok-2 detected by in situ hybridization on sections of adult worms of Schistosoma japonicum. a Semiquantification of the Sj-eggshell (Sj-es) gene in $42 \mathrm{~d}$ adult worms. $\mathbf{b}$ Histological localization of Sj-es, with antisense probe (left) and sense probe (right) of Sj-es. c Histological localization of Sj-riok-2, with antisense probe (c1-4) and sense probe (c5-8). Transcripts of Sj-es were detected in the vitellarium (v), and Sj-riok-2 was localized mainly in all reproductive organs: ovary (o), vitellarium (v), mature oocyte (mo), immature oocyte (imo), vitelloduct (vtd), ootype-surrounding area (ot), testis (t) and gastrodermis (ga). Scale-bars: $50 \mu \mathrm{m}$

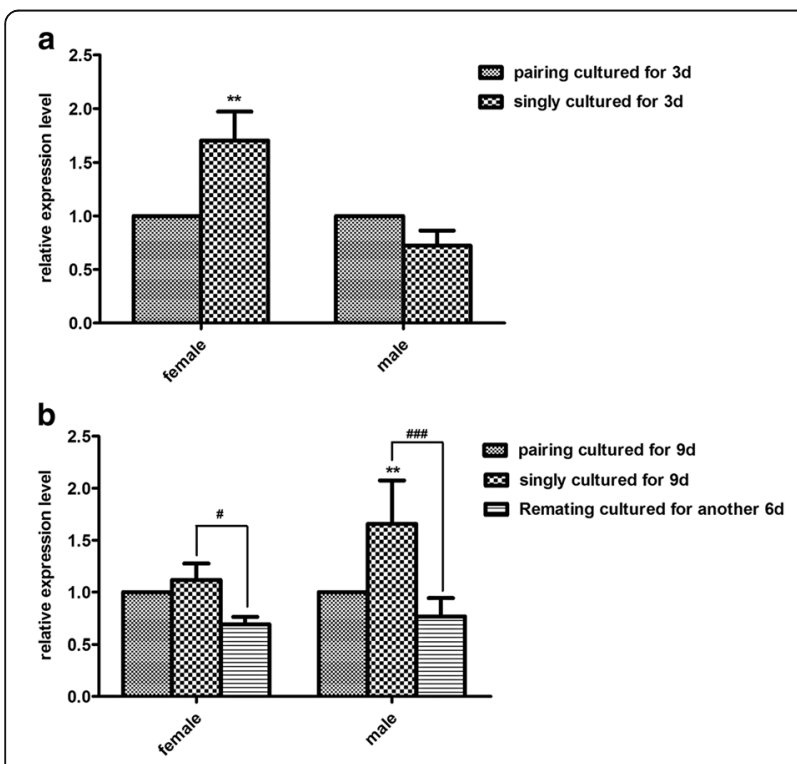

Fig. 6 Effects of pairing on the transcript level of Sj-riok-2 in the female and male Schistosoma japonicum. Worm couples, single females, and single males were cultured for $3 \mathrm{~d}(\mathbf{a})$ and for $9 \mathrm{~d}(\mathbf{b})$ in vitro. After $3 \mathrm{~d}$, the same number of single females and males were combined for re-pairing for another $6 \mathrm{~d}$ (b). Singly cultured and re-paired worms were compared with paired worms, and statistically significant differences were shown as ** $(P<0.01)$; \#/\#\#\# represent the significant differences $(P<0.05$ and $P<0.001)$ in transcript abundances between re-paired worms and single worms kinase-family member Sj-stk-6 was used as functionally unrelated negative control.

Paired worms were treated by soaking with dsRNA targeting Sj-riok-2 or/and Sj-plk-1, Sj-stk-6 or without dsRNA for $9 \mathrm{~d}$ in vitro. Compared with the untreated group (control), the transcript abundances of Sj-riok-2 in female and male worms treated with dsRNA targeting Sj-riok-2 alone or with a mixture of dsRNA targeting both Sj-riok-2 and Sjplk-1 decreased by 73-86\%, respectively $\left(F_{(4,20)}=83.69, P<\right.$ 0.0001, Fig. 7a). Similarly, transcript abundance of Sj-plk-1 in female and male worms treated with dsRNA targeting Sj-plk-1 alone or with a mixture of dsRNA targeting both Sj-plk1 and Sj-riok-2 decreased by 80-91\%, respectively $\left(F_{(4,20)}=72.73, P<0.0001\right.$, Fig. $\left.7 \mathrm{~b}\right)$. However, although treatment with dsRNA targeting Sj-plk-1 had no effect on transcription levels of Sj-riok-2 in worms, treatment with dsRNA targeting Sj-riok-2 alone caused an increase of 50\% of the transcript levels of Sj-plk-1 in male worms $\left(t_{(6)}=\right.$ 3.864, $P<0.01)$. No significant differences were detected between the control and the non-specific (Sj-stk-6) dsRNA groups.

To investigate whether Sj-riok-2 is involved in processes controlling mitoses, EdU-labeling was performed with dsRNA-treated worms as a technique to follow cell proliferation [58]. In an untreated control group, a significant amount of EdU-labeled cells were detected in the vitellarium and ovary of adult females as well as in the testis and parenchyma of adult males (Fig. 8a, e, i, $\mathrm{m})$, which indicated high mitotic activity in these organs. 


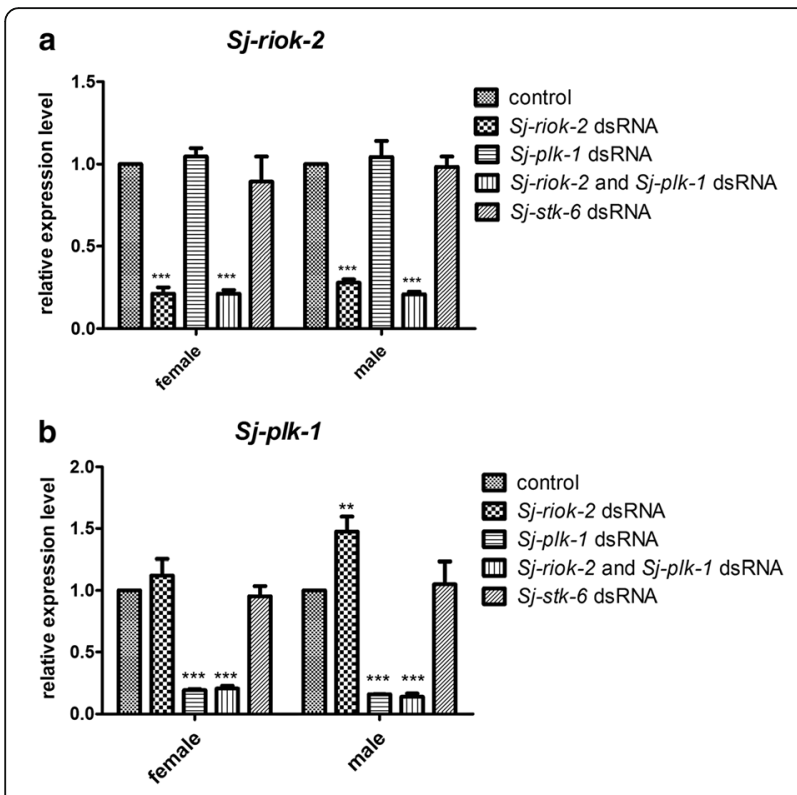

Fig. 7 Transcriptional levels of Sj-riok-2 and Sj-plk-1 in worms treated with Sj-riok-2 dsRNA or/and Sj-plk-1 dsRNA. Relative Sj-riok-2 (a) and Sj-plk-1 (b) transcript levels of females and males, respectively, after treatment with Sj-riok-2 dsRNA, Sj-plk-1 dsRNA, or both Sj-riok-2 and Sj-plk-1 dsRNAs; as controls Sj-stk-6 dsRNA or no dsRNA were used. All dsRNA-treated groups were compared with control (non-treated) groups. Data are representative of the mean \pm SD of three separate experiments. ${ }^{*},{ }^{* * *}$ indicate $P<0.01, P<0.001$

Adult worms treated with Sj-riok-2 dsRNA for $9 \mathrm{~d}$ showed a slight decrease of EdU-positive cells in the vitellarium of the female and the testis and parenchyma of the male (Fig. 8b, f, j, n). However, the number of EdU-labeled cells was remarkably reduced in the vitellarium, ovary, testis and parenchyma of worms treated with $S j-p l k-1$ dsRNA for $9 \mathrm{~d}$ (Fig. 8c, g, k, o). Worms treated with both Sj-riok-2 and $S j-p l k-1$ dsRNA had almost no EdU-labeled cells in these organs and tissue (Fig. 8d, h, l, p). A previous study has shown that developmental failures in vitellarium were due to an increase of cell apoptosis rather than decreased cell proliferation [61]. Therefore, the transcription levels of three apoptosis-associated genes of S. japonicum, caspase 3, caspase 7 and cytokine apoptosis inhibitor (CIAP) [62], were quantified after knocking down Sj-riok-2 or/and Sj-plk-1. The results showed that knocking down Sj-riok-2 had no significant impact on the transcriptional levels of the genes Sj-caspase-3 $\left(F_{(3,8)}=0.089, P=0.964\right), S j$-caspase-7 $\left(F_{(3,8)}=0.457, P=0.720\right)$ and Sj-ciap $\left(F_{(3,8)}=0.524\right.$, $P=0.678$ ) (Additional file 2: Figure S1).

Morphological analysis by CLSM finally showed no detectable changes in the size of adult worms, and the pairing stability of couples was unaffected for worms treated with $S j$-riok-2 and $S j-p l k-1$ dsRNA alone or simultaneously (Additional file 3: Figure S2). However, morphological changes were observed in the gonads of adult females treated with dsRNA for $9 \mathrm{~d}$ (Fig. 9). Although in untreated control females, small immature oocytes occur in the anterior part and larger mature oocytes in the posterior part of the ovary (Fig. 9a), the number of mature oocytes increased and dominated most of the ovary in Sj-riok-2 dsRNA-treated females (Fig. 9b). A similar trend was seen in the females treated with $S j-p l k-1$ dsRNA, where the number of immature oocytes dramatically declined while the mature oocytes were distributed throughout the ovary (Fig. 9c). Unexpectedly, females treated with both $S j-$ riok-2 and $S j-p l k-1$ dsRNA showed a similar proportional distribution of oocytes in their ovaries as control worms, with the exception of the smaller size of the ovary (Fig. 9d). Furthermore, females treated with Sj-riok-2 dsRNA showed a dilated vitelloduct, which undulates alongside the ovary (Fig. 9b). Within the vitellarium of females treated with $S j-p l k-1$ dsRNA, the number of vitelline cells decreased, and these cells appeared to be irregular and disordered (Fig. 9g). However, no significant morphological changes were observed in the females treated with both dsRNAs compared to the controls (Fig. 9h). Moreover, compared to control females (Fig. 9i), more eggs were observed inside the uterus of worms treated with Sj-riok-2 dsRNA or $S j-p l k-1$ dsRNA alone (Fig. 9j, k). Interestingly, although the amount of eggs in the uterus of the females treated with both dsRNAs was similar to the control, more abnormal eggs were found in these females (Fig. 9l). No visible content was observed in such eggs, and they seemed to be non-embryonated. However, no significant difference was found in the number of eggs laid in vitro by untreated and dsRNA-treated females (Additional file 4: Figure S3). In addition, no visible phenotype was observed in the testes or the sperm vesicle of male worms treated with any dsRNA (Fig. 9m-p).

\section{Discussion}

In the present study, the RIOK-2 encoding gene Sj-riok2 of $S$. japonicum was cloned and characterized. Alignment of the protein sequence of Sj-RIOK-2 with orthologous sequences of other species revealed that typical functional domains of this class of enzymes are also present in Sj-RIOK-2. Unlike ePKs, RIOK-2 lacks the activation loop that functions in substrate binding and recognition [63]. However, the potential substrate-binding regions predicted for the catalytic domain of Plasmodium RIOK-2 [64] are present in Sj-RIOK-2 such as the "H-R-L-G-R-I/T" motif within the flexible loop region and the M-S-Y-I/V motif within the hinge region. SjRIOK-2 exhibits a wHTH domain, which usually occurs in transcription factors or other DNA-binding proteins $[65,66]$. It has been shown previously that the wHTH domain of Archaeoglobus fulgidus RIOK-2 can nonspecifically bind to single-strand oligonucleotides [63]. In addition, as the wHTH domain of Plasmodium RIOK-2 


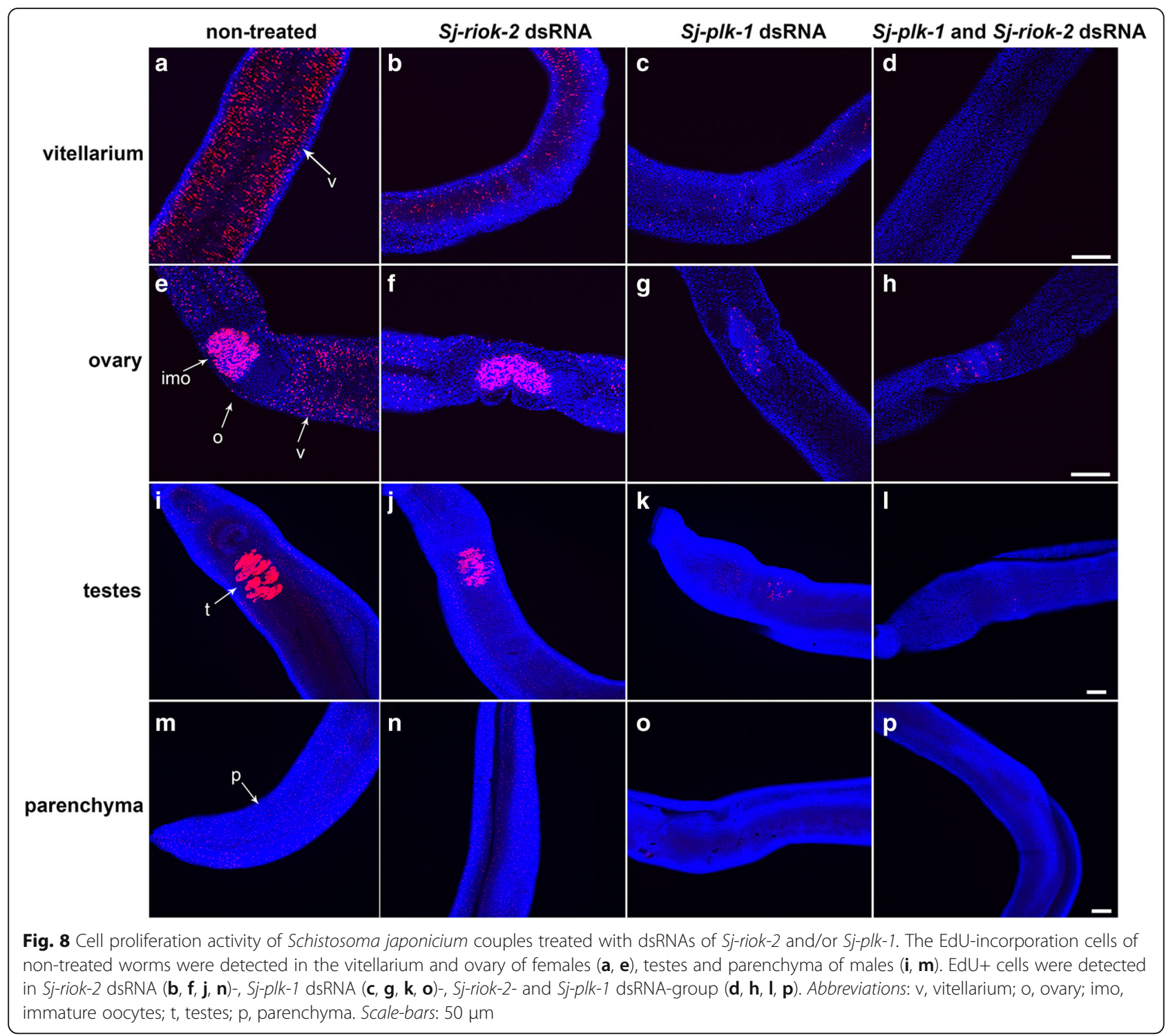

can interact with its kinase domain, it has been proposed that the interaction between DNA/RNA and wHTH could function in ribosome maturation by affecting RIOK-2 kinase activity [64]. The conservation of these regions in Sj-RIOK-2 suggests that Sj-RIOK-2 may have similar functions in S. japonicum.

In parasitic nematodes, the transcriptional profiles of riok-2 at different developmental stages have been analyzed for several species including $H$. contortus, $B$. malayi and Ascaris suum [44, 67]. In addition, in the free-living nematode C. elegans, silencing riok-2 resulted in embryonic lethality and early larval arrest [46, 47], suggesting the importance of RIOK-2 for larval growth and development. Moreover, in Drosophila, the elevated transcript levels of riok-2 in ovary likely contribute to the higher transcriptional level of riok-2 in females than males [68], indicating that riok-2 might be involved in the reproductive processes [67]. In the present results, transcriptional profiling indicated that Sj-riok-2 is transcribed in all developmental stages of $S$. japonicum. Compared with male worms, higher transcription levels were detected in females and eggs. Furthermore, in adult females, Sj-riok-2 was mainly localized in the reproductive organs, suggesting that Sj-riok-2 could be involved in female reproductive biology in S. japonicum. Previous studies [69-71] have indicated an influence of pairing on the expression of genes in schistosome females, particularly genes with functions in the reproductive organs. Pairing experiments in our study showed that, compared with paired females, the transcription level of Sj-riok-2 was higher in unpaired females than in re-paired females. Thus, it seems likely that Sj-riok-2 is involved in pairinginfluenced processes associated with female maturation and sexual maintenance. 


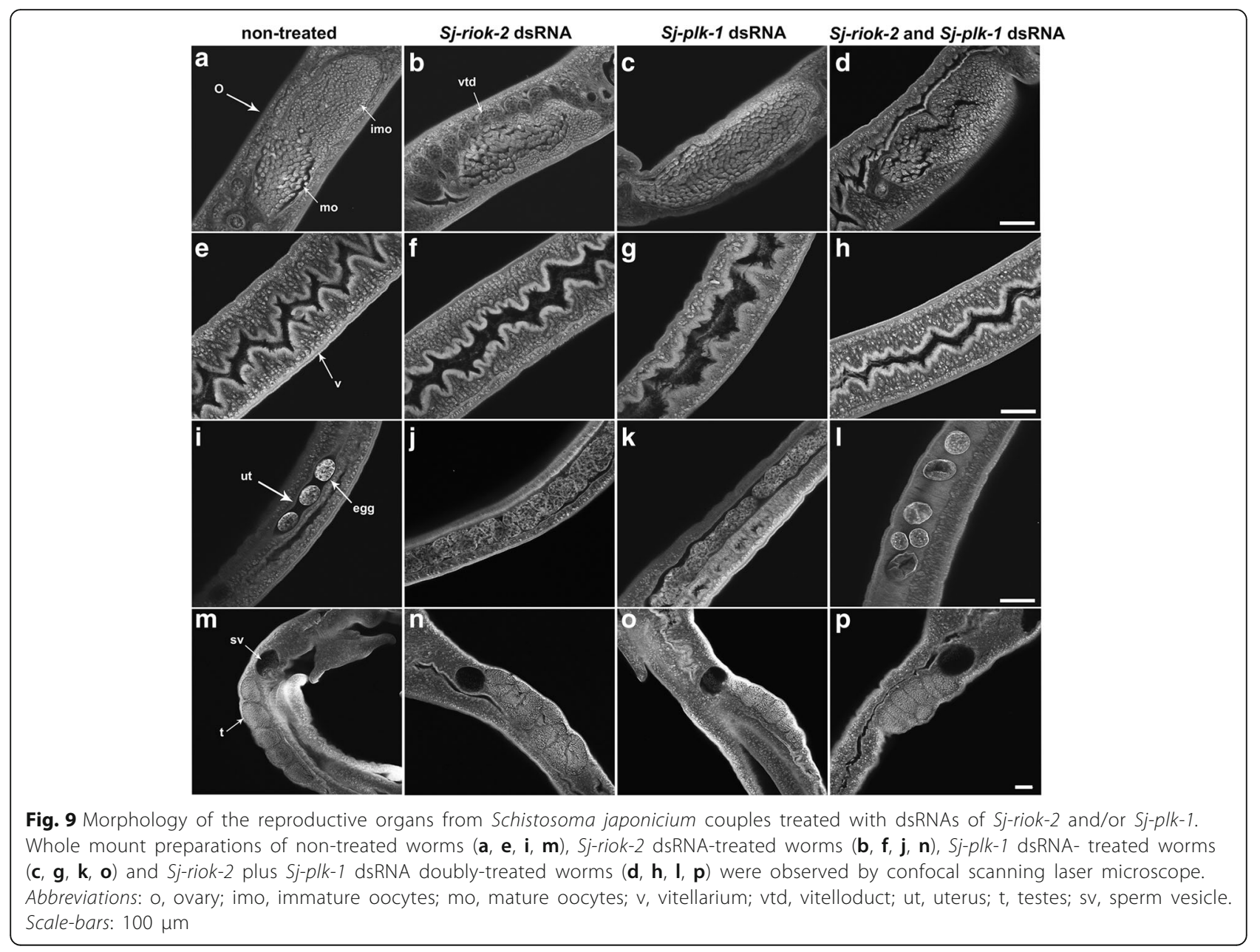

There are conflicting results from the literature about the role of RIOK-2 kinases with respect to mitogenic activity. The depletion of RIOK-2 in yeast did not trigger cell-cycle arrest in any stage [38]. In HeLa cells, knockdown of riok-2 was found to accelerate mitotic exit, whereas its over-expression did not affect mitotic entry [42]. In a Drosophila glioblastoma model, suppression of riok-2 caused mitotic entry arrest and apoptosis by inducing p53 activity [43]. In first experiments using the Xenopus oocyte system, which had been shown before to be suitable for studying kinases [16, 21, 22], it was shown that Sj-riok-2 delayed the G2-M transition during meiosis using germinal vesicle breakdown assays as read out (Additional file 5: Figure S4). So knockdown Sj-riok-2 may resume or accelerate meiosis/mitosis entrance. The observation that the number of EdU-labeled cells is less abundant in the vitellarium and testes following knockdown of Sj-riok-2 suggests that this kinase can influence the cell cycle at the G1 and/or S level. Therefore, we hypothesize that Sj-riok-2 acts in dividing cells as a balancing element to avoid premature mitosis. Also in the ovary a slight decrease in EdU- positive cells was observed which, however, was not as high as in the other gonad tissues. This indicates that Sj-riok-2 may fulfill a function in all schistosome tissues with high proliferative capacity. However, this effect could not be completely monitored by EdU labeling that concerns only the $\mathrm{S}$ phase. In contrast, the $p l k-1$ knockdown completely inhibits EdU labeling because PLK-1 strongly controls $\mathrm{S}$ phase.

The hypothesis of Sj-riok-2 as a balancer of mitosis is supported by studies in HeLa cells, in which riok-2 knockdown accelerated mitotic exit [42]. This indicated that the loss of riok-2 function accelerated cell-cycle progression to promote post-mitotic differentiation events. In S. japonicum, after meiosis, small oogonia develop to primary mature oocytes with a central nucleus that dominate in the posterior part of the ovary. Upon Sj-riok-2 knockdown, the number of mature oocytes increased. This suggests that less oogonia entered mitotic division ahead of meiosis I and that knockdown of Sj-riok-2 could promote oocyte maturation towards primary oocytes. In addition, the dilated vitelloduct found upon knockdown may result from an increased number of S4-stage mature 
vitellocytes, which provide material and nutrition for more eggs production. Compared with the control group, more eggs accumulated in uterus of Sj-riok-2 dsRNA-treated females. However, there was no significant difference in the number of eggs laid in vitro between the control group and the Sj-riok-2 dsRNA-treated group. This can be explained by an increased capacity of egg formation, without ovulation being able to keep pace with egg production, leading to egg accumulation in the uterus. Finally, Sj-riok2 has also been localized to the ootype-surrounding area, which suggests an additional role of this kinase for eggformation processes.

A previous study proposed that, as an important regulator of Akt signaling pathway, RIOK-2 might act as a ribosomal stress checkpoint to either progress the cell cycle after the completion of ribosomal maturation or activate the apoptosis pathway upon disruption of ribosomal biosynthesis [43, 67]. However, knocking down Sjriok-2 had no significant impact on the transcriptional levels of three apoptosis-associated genes in S. japonicum, suggesting that riok-2 could be involved in oocytes or vitelline cell maturation that was independent of activating apoptosis. In the cell cycle, the activation of anaphase-promoting complex or cyclosome (APC/C), a conserved multi-subunit E3 ubiquitin (Ub) ligase is required for promoting anaphase initiation and mitosis exit, but preventing meiotic resumption in prophase I-arrested mouse oocytes by degrading its numerous substrates [72-77]. RIOK-2 was identified to interact with APC complex subunits, Apc10 and Apc3 [42], and Apc10 interacting with Apc3 [78]. In addition, Apc10 and Apc3, as important substrate-and activator-binding subunits, respectively $[79,80]$, assembled with catalytic core member Apc 11 and then contributed to the substrate ubiquitination $[74,81,82]$, suggesting that RIOK-2 might be a part of APC/C complex core targeting substrates or proteins [42]. According to the above results, we assume that $\mathrm{Sj}$-RIOK-2 may activate APC/C complex to degrade cyclin B, then induced G2-M transition arrested. This was also in consistent with the result that Sj-riok-2 delayed meiotic resumption in Xenopus oocytes.

Previous studies indicated roles of PLK-1 in multiple mitotic events such as CDK1 activation, centrosome maturation, spindle assembly and $\mathrm{APC} / \mathrm{C}$ regulation [83]. Inhibition of $p l k-1$ by specific inhibitors or RNAi arrested G2/M transition in human cells [84] and Xenopus oocytes [24], indicating that the suppression of plk-1 induced the termination of cell proliferation by arresting both mitotic and meiotic progresses. In HeLa cells, PLK-1 can phosphorylate RIOK-2 to regulate mitotic progression [42]. In $S$. mansoni, Sm-PLK-1 was identified as a mitotically active kinase, it was mainly localized in the reproductive organs and shown to be required for oogenesis and spermatogenesis [24]. With respect of the co-localization in the gonads, a cooperation of both molecules seemed possible. Knocking down Sj-plk-1 induced a significant reduction of EdUlabelled cells in the gonads, because cell proliferation was inhibited. A similar, but much weaker effect was observed upon silencing Sj-riok-2 activity. In Sj-riok-2 and Sj-plk-1 double knockdown worms, the smallest number of EdU-labeled cells was detected. These findings point to an additive effect, indicating that both molecules appear to cooperate. Previously it was found that PLK-1 could mediate the phosphorylation of RIOK-2 to regulate mitotic exit [42]. This observation supports the proposal of a cooperating role of both proteins, whereas PLK-1 might have a superior function in supporting mitotic processes.

Finally, CLSM analyses demonstrated that in Sj-plk-1 dsRNA-treated females, the number of mature oocytes had increased compared to controls. This phenotype is consistent with the morphological changes observed inside the ovary of $S$. mansoni females treated with a PLK-1 inhibitor, which probably caused a mitotic arrest and the termination of oogonia divisions [24, 84]. Given that knockdown of Sj-plk-1 did not affect the transcription level of apoptosis-associated genes (Additional file 2: Figure S1), the significant reduction of the number of oogonia might have been caused by an arrested cell cycle, while post-mitotic, differentiating oocytes expand into the complete cavity of the ovary. Although a similar phenotype was also observed in S. japonicum females after knocking-down $S j$-riok-2, it was not as strong as that seen for PLK-1.Thus we assume that Sj-riok-2 and Sj-plk-1 may play cooperating roles in cell-cycle control in the gonads, and Sj-riok-2 may counter balance the activity of Sj-plk-1. The similar gonad morphologies of females of the double knockdown and control groups support this hypothesis.

\section{Conclusions}

This study represents the first functional characterization of RIOK-2 in platyhelminthes. We cloned and characterized a RIO-2 kinase encoding gene from S. japonicum (Sj-riok-2). It exhibits typical structural features of orthologs from other eukaryotic species and Sj-riok-2 is transcribed in different developmental stages of $S$. japonicum with highest abundance in 42 day-old females. In both males and females, transcription occurred pairing-dependently, and transcripts were localized mainly to the reproductive organs. Knocking-down Sj-riok-2 reduced cell proliferation in the gonads and caused an increase of the amount of mature oocytes in the ovary as well as an accumulation of eggs in the uterus. Thus, our data demonstrate that Sj-riok-2 is involved in key processes controlling the reproductive biology of female S. japonicum. 


\section{Additional files}

Additional file 1: Table S1. DNA sequences of oligonucleotide primers used in the present study. These primers were employed for the isolation of $3^{\prime} C D N A$ of Sj-riok-2 and for the amplification of DNA template for dsRNA synthesis of Sj-riok-2, Sj-plk-1 and Sj-stk-6 genes using PCR-based approaches and for real-time (RT) PCR quantification. (DOCX 14 kb)

Additional file 2: Figure S1. Transcriptional levels of the apoptosisassociated genes caspase 3, caspase 9 and cytokine apoptosis inhibitor (CIAP) in female S. japonicum treated with specific Sj-riok-2 dsRNA or/and Sj-plk-1 dsRNA. Relative Sj-caspase-3, Sj-caspase-9 and Sj-ciap transcript levels of females after treatment with Sj-riok-2 dsRNA, Sj-plk-1 dsRNA or both Sj-riok-2 and Sj-plk-1 dsRNA were detected by RT-PCR, respectively. Data are representative of the mean \pm SD of three separate experiments. (TIFF $167 \mathrm{~kb}$ )

Additional file 3: Figure S2. Comparison of the worm length between the control group and Sj-riok-2 dsRNA- or/and Sj-plk-1 dsRNA-treated group. The body length of female and male worms was measured under microscope after in vitro culture for $9 \mathrm{~d}$, respectively. No significant difference was found among the different groups. Data are representative of the mean \pm SD of three separate experiments. (TIFF $607 \mathrm{~kb}$ )

Additional file 4: Figure S3. Egg count upon RNAi treatment. The numbers of eggs laid ex vivo by female worms from the control group and the Sj-riok-2 dsRNA- or/and Sj-plk-1 dsRNA-treated groups during 3-5 days, 5-7 days, 7-9 days were counted manually. No significant differences were detected among these groups. Data are representative of the mean \pm SD of three separate experiments. (TIFF $469 \mathrm{~kb}$ )

Additional file 5: Figure S4. Sj-riok-2 activity in Xenopus oocyte germinal vesicle break down (GVBD) assays. Capped messenger RNA (CRNA) of Sj-riok-2 was microinjected into Xenopus laevis stage $\mathrm{VI}$ oocytes according to a standard protocol $[21,22]$. Each oocyte was injected with $60 \mathrm{nl}(60 \mathrm{ng}) \mathrm{CRNA}$ in the equatorial region and incubated at $19{ }^{\circ} \mathrm{C}$ in ND96 medium. Results are expressed as the percentages of the number of mature oocytes found in samples injected with Sj-riok-2 cRNA or uninjected. After 10 h, GVBD was detected in all uninjected oocytes by the appearance of a white spot at the center of the animal pole. Compared to the uninjected group, the GVBD oocytes were decreased in Sj-riok-2 cRNA injected oocytes. (TIFF $35 \mathrm{~kb}$ )

\section{Abbreviations}

aPK: Atypical protein kinase; CLSM: Confocal laser scanning microcopy; EdU: 5-ethynyl-2'-deoxyuridine; ePK: Eukaryotic protein kinase; RIO: Right open reading frame

\section{Acknowledgements}

The authors would like to thank Professor Kemei Peng for technical assistance.

\section{Funding}

This study was supported by the National Key Basic Research Program (973 Program) of China (Grant No. 2015CB150300) and the Fundamental Research Funds for the Central Universities (Grant No. 2662015PY180) to MH, by the National Natural Science Foundation (Grant No. 31201897) to QY, and by Huazhong Agricultural University Scientific \& Technological Self-innovation Foundation (Program No. 2015RC005) to RBG.

\section{Availability of data and materials}

The Sj-riok-2 sequence was available in GenBank (accession no. KY884990) (https://www.ncbi.nlm.nih.gov/nuccore/KY884990).

\section{Authors' contributions}

$\mathrm{MH}$ and $\mathrm{CG}$ conceived and designed the study with the input from $\mathrm{CD}$ and RG. $L Z, X H, Q Y, Y L$ performed the experiments and analyzed the data. MM, $Y Z$, JZ contributed reagents/materials/analysis tools. LZ, CG, MH, QY, XH and RG contributed to the writing of the manuscript. All authors read and approved the final manuscript.

\section{Ethics approval and consent to participate}

The care and maintenance of experimental mice in this study was approved by the Institutional Animal Care and Use Committee of Huazhong Agricultural University according to the Regulations for the Administration of Affairs Concerning Experimental Animals of Hubei Province, P.R. China.

\section{Consent for publication}

Not applicable.

\section{Competing interests}

The authors declare that they have no competing interests.

\section{Publisher's Note}

Springer Nature remains neutral with regard to jurisdictional claims in published maps and institutional affiliations.

\section{Author details}

${ }^{1}$ State Key Laboratory of Agricultural Microbiology, College of Veterinary Medicine, Huazhong Agricultural University, Wuhan, People's Republic of China. ${ }^{2}$ Institute of Parasitology, BFS, Justus-Liebig-University Giessen, Giessen, Germany. ${ }^{3}$ Faculty of Veterinary and Agricultural Sciences, The University of Melbourne, Parkville, Melbourne, Australia. ${ }^{4} \mathrm{CIIL}$ - Center for Infection and Immunity of Lille Inserm, University Lille, Lille, France.

Received: 1 November 2017 Accepted: 5 November 2017

Published online: 12 December 2017

\section{References}

1. Colley DG, Bustinduy AL, Secor WE, King CH. Human schistosomiasis. Lancet. 2014;383:2253-64

2. Tebeje BM, Harvie M, You H, Loukas A, McManus DP. Schistosomiasis vaccines: where do we stand? Parasit Vectors. 2016:9:528

3. Xiao SH, Catto BA, Webster LT Jr. Effects of praziquantel on different developmental stages of Schistosoma mansoni in vitro and in vivo. J Infect Dis. 1985;151:1130-7.

4. Pica-Mattoccia L, Cioli D. Sex- and stage-related sensitivity of Schistosoma mansoni to in vivo and in vitro praziquantel treatment. Int J Parasitol. 2004; 34:527-33.

5. Botros S, Sayed H, Amer N, El-Ghannam M, Bennett JL, Day TA. Current status of sensitivity to praziquantel in a focus of potential drug resistance in Egypt. Int J Parasitol. 2005;35:787-91.

6. Doenhoff MJ, Pica-Mattoccia L. Praziquantel for the treatment of schistosomiasis: its use for control in areas with endemic disease and prospects for drug resistance. Expert Rev Anti-Infect Ther. 2006;4:199-210.

7. Melman SD, Steinauer ML, Cunningham C, Kubatko LS, Mwangi IN, Wynn NB, et al. Reduced susceptibility to praziquantel among naturally occurring Kenyan isolates of Schistosoma mansoni. PLoS Negl Trop Dis. 2009:3:e504.

8. Pica-Mattoccia L, Doenhoff MJ, Valle C, Basso A, Troiani AR, Liberti P, et al. Genetic analysis of decreased praziquantel sensitivity in a laboratory strain of Schistosoma mansoni. Acta Trop. 2009;111:82-5.

9. Doenhoff MJ, Cioli D, Utzinger J. Praziquantel: mechanisms of action, resistance and new derivatives for schistosomiasis. Curr Opin Infect Dis. 2008:21:659-67.

10. James CE, Hudson AL, Davey MW. An update on P-glycoprotein and drug resistance in Schistosoma mansoni. Trends Parasitol. 2009;25:538-9.

11. Ross AG, Bartley PB, Sleigh AC, Olds GR, Li Y, Williams GM, et al. Schistosomiasis. N Engl J Med. 2002;346:1212-20.

12. Popiel I, Basch PF. Reproductive development of female Schistosoma mansoni (Digenea: Schistosomatidae) following bisexual pairing of worms and worm segments. J Exp Zool. 1984:232:141-50.

13. Kunz W. Schistosome male-female interaction: induction of germ-cell differentiation. Trends Parasitol. 2001;17:227-31.

14. Quack T, Beckmann S, Grevelding CG. Schistosomiasis and the molecular biology of the male-female interaction of S. mansoni. Berl Munch Tierarztl Wochenschr. 2006:119:365-72

15. LoVerde PT, Andrade LF, Oliveira G. Signal transduction regulates schistosome reproductive biology. Curr Opin Microbiol. 2009:12:422-8.

16. Beckmann S, Quack T, Burmeister C, Buro C, Long T, Dissous C, et al. Schistosoma mansoni: signal transduction processes during the development of the reproductive organs. Parasitology. 2010;137:497-520. 
17. Cheng GF, Lin JJ, Feng XG, Fu ZQ, Jin YM, Yuan CX, et al. Proteomic analysis of differentially expressed proteins between the male and female worm of Schistosoma japonicum after pairing. Proteomics. 2005;5:511-21.

18. Hanks SK, Quinn AM, Hunter T. The protein kinase family: conserved features and deduced phylogeny of the catalytic domains. Science. 1988;241:42-52.

19. Manning G, Whyte DB, Martinez R, Hunter T, Sudarsanam S. The protein kinase complement of the human genome. Science. 2002;298:1912-34.

20. Scheeff ED, Bourne PE. Structural evolution of the protein kinase-like superfamily. PLoS Comput Biol. 2005;1:e49.

21. Beckmann S, Buro C, Dissous C, Hirzmann J, Grevelding CG. The Syk kinase SmTK4 of Schistosoma mansoni is involved in the regulation of spermatogenesis and oogenesis. PLoS Pathog. 2010;6:e1000769.

22. Beckmann S, Hahnel S, Cailliau K, Vanderstraete M, Browaeys E, Dissous C, et al. Characterization of the Src/Abl hybrid kinase SmTK6 of Schistosoma mansoni. J Biol Chem. 2011;286:42325-36.

23. Dissous C, Grevelding CG, Long T. Schistosoma mansoni polo-like kinases and their function in control of mitosis and parasite reproduction. An Acad Bras Cienc. 2011;83:627-35.

24. Long T, Cailliau K, Beckmann S, Browaeys E, Trolet J, Grevelding CG, et al. Schistosoma mansoni polo-like kinase 1: a mitotic kinase with key functions in parasite reproduction. Int J Parasitol. 2010;40:1075-86.

25. Long T, Vanderstraete M, Cailliau K, Morel M, Lescuyer A, Gouignard N, et al. SmSak, the second polo-like kinase of the helminth parasite Schistosoma mansoni: conserved and unexpected roles in meiosis. PLoS One. 2012;7:e40045.

26. Kapp K, Knobloch J, Schussler P, Sroka S, Lammers R, Kunz W, et al. The Schistosoma mansoni Src kinase TK3 is expressed in the gonads and likely involved in cytoskeletal organization. Mol Biochem Parasitol. 2004;138:171-82.

27. Leutner S, Beckmann S, Grevelding CG. Characterization of the CGMPdependent protein kinase SmcGK1 of Schistosoma mansoni. An Acad Bras Cienc. 2011;83:637-48.

28. Beckmann S, Grevelding CG. Imatinib has a fatal impact on morphology, pairing stability and survival of adult Schistosoma mansoni in vitro. Int J Parasitol. 2010;40:521-6.

29. Andrade LFD. Regulation of Schistosoma mansoni development and reproduction by the mitogen-activated protein kinase signaling pathway. PLoS Negl Trop Dis. 2014;8:e2949.

30. Ressurreicao M, De Saram P, Kirk RS, Rollinson D, Emery AM, Page NM, et al. Protein kinase $C$ and extracellular signal-regulated kinase regulate movement, attachment, pairing and egg release in Schistosoma mansoni. PLoS Negl Trop Dis. 2014;8:e2924.

31. Walker AJ, Ressurreicao M, Rothermel R. Exploring the function of protein kinases in schistosomes: perspectives from the laboratory and from comparative genomics. Front Genet. 2014;5:229.

32. Vanderstraete M, Gouignard N, Cailliau K, Morel M, Hahnel S, Leutner S, et al. Venus kinase receptors control reproduction in the platyhelminth parasite Schistosoma mansoni. PLoS Pathog. 2014;10:e1004138.

33. Angermayr M, Bandlow W. The type of basal promoter determines the regulated or constitutive mode of transcription in the common control region of the yeast gene pair GCY1/RIO1. J Biol Chem. 1997;272:31630-5.

34. LaRonde-LeBlanc N, Wlodawer A. A family portrait of the RIO kinases. J Biol Chem. 2005;280:37297-300.

35. LaRonde-LeBlanc N, Wlodawer A. The RIO kinases: an atypical protein kinase family required for ribosome biogenesis and cell cycle progression. Biochim Biophys Acta. 1754;2005:14-24.

36. Zemp I, Wild T, O'Donohue MF, Wandrey F, Widmann B, Gleizes PE, et al. Distinct cytoplasmic maturation steps of 405 ribosomal subunit precursors require hRio2. J Cell Biol. 2009;185:1167-80.

37. Rouquette J, Choesmel V, Gleizes PE. Nuclear export and cytoplasmic processing of precursors to the 405 ribosomal subunits in mammalian cells. EMBO J. 2005;24:2862-72.

38. Geerlings TH, Faber AW, Bister MD, Vos JC, Raue HA. Rio2p, an evolutionarily conserved, low abundant protein kinase essential for processing of $20 \mathrm{~S}$ pre-rRNA in Saccharomyces cerevisiae. J Biol Chem. 2003;278:22537-45.

39. Vanrobays E, Gelugne JP, Gleizes PE, Caizergues-Ferrer M. Late cytoplasmic maturation of the small ribosomal subunit requires $\mathrm{RIO}$ proteins in Saccharomyces cerevisiae. Mol Cell Biol. 2003;23:2083-95.

40. Strunk BS, Novak MN, Young CL, Karbstein K. A translation-like cycle is a quality control checkpoint for maturing $40 S$ ribosome subunits. Cell. 2012;150:111-21.

41. Ferreira-Cerca S, Sagar V, Schafer T, Diop M, Wesseling AM, Lu H, et al. ATPase-dependent role of the atypical kinase Rio2 on the evolving pre-40S ribosomal subunit. Nat Struct Mol Biol. 2012;19:1316-23.
42. Liu T, Deng M, Li J, Tong X, Wei Q, Ye X. Phosphorylation of right open reading frame 2 (Rio2) protein kinase by polo-like kinase 1 regulates mitotic progression. J Biol Chem. 2011;286:36352-60.

43. Read RD, Fenton TR, Gomez GG, Wykosky J, Vandenberg SR, Babic I, et al. A kinome-wide RNAi screen in Drosophila glia reveals that the RIO kinases mediate cell proliferation and survival through TORC2-Akt signaling in glioblastoma. PLoS Genet. 2013;9:e1003253.

44. Campbell BE, Boag PR, Hofmann A, Cantacessi C, Wang CK, Taylor P, et al. Atypical (RIO) protein kinases from Haemonchus contortus - promise as new targets for nematocidal drugs. Biotechnol Adv. 2011;29:338-50.

45. Breugelmans B, Jex AR, Korhonen PK, Mangiola S, Young ND, Sternberg PW, et al. Bioinformatic explation of RIO protein kinases of parasitic and freeliving nematodesor. Int J Parasitol. 2014;44:827-36.

46. Sonnichsen B, Koski LB, Walsh A, Marschall P, Neumann B, Brehm M, et al. Full-genome RNAi profiling of early embryogenesis in Caenorhabditis elegans. Nature. 2005;434:462-9.

47. Mendes TK, Novakovic S, Raymant G, Bertram SE, Esmaillie R, Nadarajan S, et al. Investigating the role of RIO protein kinases in Caenorhabditis elegans. PLoS One. 2015;10:e0117444.

48. Chen PH, Zhou SL. Clutivation in vitro of medical parasites. Beijing: Science Press; 1995.

49. Liu LY, Yu XB, Luo SH, Fang JM. Quick isolation and purification of Schistosoma japonicum eggs and their total RNA. Chin J Zoonoses. 1997;02:3.

50. Bairoch A. The PROSITE dictionary of sites and patterns in proteins, its current status. Nucleic Acids Res. 1993;21:3097-103.

51. Bateman A, Birney E, Durbin R, Eddy SR, Howe KL, Sonnhammer EL. The Pfam protein families database. Nucleic Acids Res. 2000;28:263-6.

52. Tamura K, Peterson D, Peterson N, Stecher G, Nei M, Kumar S. MEGA5: Molecular Evolutionary Genetics Analysis using maximum likelihood, evolutionary distance, and maximum parsimony methods. Mol Biol Evol. 2011;28:2731-9.

53. Cheng GF, Fu ZQ, Lin JJ, Shi Y, Zhou YC, Jin YX, et al. In vitro and in vivo evaluation of small interference RNA-mediated gynaecophoral canal protein silencing in Schistosoma japonicum. J Gene Med. 2009;11:412-21.

54. Liu P, Shi Y, Yang Y, Cao Y, Li H, Liu J, et al. Schistosoma japonicum UDPglucose 4-epimerase protein is located on the tegument and induces moderate protection against challenge infection. PLoS One. 2012;7:e42050.

55. Livak KJ, Schmittgen TD. Analysis of relative gene expression data using real-time quantitative PCR and the $2^{-\Delta \Delta C T}$ method. Methods. 2001;25:402-8.

56. Quack T, Knobloch J, Beckmann S, Vicogne J, Dissous C, Grevelding CG. The formin-homology protein SmDia interacts with the Src kinase SmTK and the GTPase SmRho1 in the gonads of Schistosoma mansoni. PLoS One. 2009;4:e6998.

57. Bobek LA, Rekosh DM, LoVerde PT. Schistosoma japonicum: analysis of eggshell protein genes, their expression, and comparison with similar genes from other schistosomes. Exp Parasitol. 1991;72:381-90.

58. Collins JJ III, Wang B, Lambrus BG, Tharp ME, lyer H, Newmark PA. Adult somatic stem cells in the human parasite Schistosoma mansoni. Nature. 2013:494:476-9.

59. Angermayr M, Roidl A, Bandlow W. Yeast Rio1p is the founding member of a novel subfamily of protein serine kinases involved in the control of cell cycle progression. Mol Microbiol. 2002;44:309-24.

60. Koster B, Dargatz H, Schroder J, Hirzmann J, Haarmann C, Symmons P, et al. Identification and localisation of the products of a putative eggshell precursor gene in the vitellarium of Schistosoma mansoni. Mol Biochem Parasitol. 1988;31:183-98.

61. Galanti SE, Huang SC, Pearce EJ. Cell death and reproductive regression in female Schistosoma mansoni. PLoS Negl Trop Dis. 2012;6:e1509.

62. Peng J, Gobert GN, Hong Y, Jiang W, Han H, McManus DP, et al. Apoptosis governs the elimination of Schistosoma japonicum from the non-permissive host Microtus fortis. PLoS One. 2011;6:e21109.

63. LaRonde-LeBlanc N, Wlodawer A. Crystal structure of a. Fulgidus Rio2 defines a new family of serine protein kinases. Structure. 2004;12:1585-94.

64. Trivedi V, Nag S. In silico characterization of atypical kinase PFD0975w from Plasmodium kinome: a suitable target for drug discovery. Chem Biol Drug Des. 2012;79:600-609.

65. Dong G, Chakshusmathi G, Wolin SL, Reinisch KM. Structure of the la motif: a winged helix domain mediates RNA binding via a conserved aromatic patch. EMBO J. 2004;23:1000-7.

66. Wolberger C, Campbell R. New perch for the winged helix. Nat Struct Biol. 2000;7:261-2. 
67. Breugelmans B, Jex AR, Korhonen PK, Mangiola S, Young ND, Sternberg PW, et al. Bioinformatic exploration of RIO protein kinases of parasitic and freeliving nematodes. Int J Parasitol. 2014;44:827-36.

68. Graveley BR, Brooks AN, Carlson JW, Duff MO, Landolin JM, Yang L, et al. The developmental transcriptome of Drosophila melanogaster. Nature. 2011; 471:473-9.

69. Cai P, Liu S, Piao X, Hou N, Gobert GN, McManus DP, et al. Comprehensive transcriptome analysis of sex-biased expressed genes reveals discrete biological and physiological features of male and female Schistosoma japonicum. PLoS Negl Trop Dis. 2016;10:e0004684.

70. Cogswell AA, Kommer VP, Williams DL. Transcriptional analysis of a unique set of genes involved in Schistosoma mansoni female reproductive biology. PLoS Negl Trop Dis. 2012;6:e1907.

71. Lu ZG, Sessler F, Holroyd N, Hahnel S, Quack T, Berriman M, et al. Schistosome sex matters: a deep view into gonad-specific and pairingdependent transcriptomes reveals a complex gender interplay. Sci Rep. 2016;6:31150.

72. Reis A, Chang HY, Levasseur M, Jones KT. APC(cdh1) activity in mouse oocytes prevents entry into the first meiotic division. Nat Cell Biol. 2006;8:539-40.

73. Holt JE, Weaver J, Jones KT. Spatial regulation of APCCdh1-induced cyclin B1 degradation maintains G2 arrest in mouse oocytes. Development. 2010; 137:1297-304.

74. Primorac I, Musacchio A. Panta rhei: the APC/C at steady state. J Cell Biol. 2013;201:177-89.

75. Murray AW, Solomon MJ, Kirschner MW. The role of cyclin synthesis and degradation in the control of maturation promoting factor activity. Nature. 1989;339:280-6.

76. Shirayama M, Toth A, Galova M, Nasmyth K. APC(Cdc20) promotes exit from mitosis by destroying the anaphase inhibitor Pds 1 and cyclin Clb5. Nature. 1999;402:203-7.

77. Pines J. Cubism and the cell cycle: the many faces of the APC/C. Nat Rev Mol Cell Biol. 2011;12:427-38.

78. Wendt KS, Vodermaier HC, Jacob U, Gieffers C, Gmachl M, Peters JM, et al. Crystal structure of the APC10/DOC1 subunit of the human anaphasepromoting complex. Nat Struct Biol. 2001;8:784-8.

79. Passmore LA, McCormack EA, Au SW, Paul A, Willison KR, Harper JW, et al. Doc1 mediates the activity of the anaphase-promoting complex by contributing to substrate recognition. EMBO J. 2003;22:786-96.

80. Matyskiela ME, Morgan DO. Analysis of activator-binding sites on the APC/C supports a cooperative substrate-binding mechanism. Mol Cell. 2009;34:68-80.

81. Yu H, Peters JM, King RW, Page AM, Hieter P, Kirschner MW. Identification of a cullin homology region in a subunit of the anaphase-promoting complex. Science. 1998;279:1219-22.

82. Zachariae W, Shevchenko A, Andrews PD, Ciosk R, Galova M, Stark MJ, et al. Mass spectrometric analysis of the anaphase-promoting complex from yeast: identification of a subunit related to cullins. Science. 1998;279:1216-9.

83. Xie S, Xie B, Lee MY, Dai W. Regulation of cell cycle checkpoints by polo-like kinases. Oncogene. 2005;24:277-86.

84. Steegmaier M, Hoffmann M, Baum A, Lenart P, Petronczki M, Krssak M, et al. BI 2536, a potent and selective inhibitor of polo-like kinase 1, inhibits tumor growth in vivo. Curr Biol. 2007;17:316-22.

\section{Submit your next manuscript to BioMed Central and we will help you at every step:}

- We accept pre-submission inquiries

- Our selector tool helps you to find the most relevant journal

- We provide round the clock customer support

- Convenient online submission

- Thorough peer review

- Inclusion in PubMed and all major indexing services

- Maximum visibility for your research

Submit your manuscript at www.biomedcentral.com/submit
Biomed Central 